\title{
Research and Design of Teaching Evaluation System based on Fuzzy Model
}

\author{
Jianting Shi ${ }^{\mathrm{a}}$, Chunyou Dong ${ }^{\mathrm{b}}$, Jiuyang Hou ${ }^{\mathrm{a}}$ \\ ${ }^{a}$ Computer and Information Engineering Department \\ ${ }^{b}$ Graduate college Heilongjiang Institute of Science and Technology Harbin, China
}

\begin{abstract}
Teaching quality evaluation is an effective method to test teaching. Teaching quality evaluation is a typical uncertainty problem. With my school's teaching evaluation indexes, this paper proposes the design scheme of teaching evaluation system based on fuzzy model, in accordance with experts knowledge and experience. The system could make an accurate and efficient evaluation for teaching quality and provide a significant reference value.
\end{abstract}

Index Terms: teaching quality evaluation; teaching evaluation index; fuzzy model

(C) 2012 Published by MECS Publisher. Selection and/or peer review under responsibility of the International Conference on E-Business System and Education Technology

\section{Introduction}

Since 1999, with the university enrollment expansion, China's higher education enrollment rate increased year by year, has reached 21\% in 2006, marking the popularization of higher education into the development stage. Consequently, the overall size of higher education ranks first in the world [1]. Teaching quality evaluation is a very important part, how to improve the quality has become a new situation, the level of higher education is a key step on a new move. How to build a scientific, rational and a high level intelligent of teaching monitoring and evaluation system for timely feedback on the problems and needs, comprehensively improve the quality of teaching and training, is an important issue solved for the sound development of current higher education [2]. As the teaching process includes both teaching and learning, it's much more complicated to evaluate teaching quality than product quality. There are many measured indexes and existed uncertain factors, supervisory experts often use vague comments, such as very good, good, fair etc. So this paper proposes teaching quality evaluation system based on fuzzy model and provides a significant reference value.

\footnotetext{
* Corresponding author.

E-mail address: nancyjts1849@yahoo.com.cn
} 


\section{Teaching quality evaluation index}

With educational evaluation theory and technology, a certain quality requirements are made by value judgments of teaching quality evaluation on the teaching process and results. The purpose is to improve teaching quality and give a qualified certification to evaluated objects. Traditional evaluation model has a certain rationality to evaluate teaching quality and talent cultivation quality, but the scientific index is not high enough. The main problems are: (1) The index system can not reflect the views of teachers and students; (2) The index system ignores the differences between public basic courses and specialized courses, compulsory courses and elective courses, and theory and practice courses. (3) The effect of human factors reduces the reliability of evaluation result. In addition, the evaluation system is a complex system with both quantitative and qualitative indicators, using a combination of two types of indicators can improve the evaluation of the results of the fairness, rationality and objectivity. Considering various factors and the combination of the present teaching and characteristics of new developments, a teaching quality system model of secondary indicators is established to evaluate the following aspects, shown as table 1.

TABLE I. TEACHING QUALITY EVALUATION INDEX

\begin{tabular}{|c|c|}
\hline First-level index & Secondary-level index \\
\hline \multirow{3}{*}{ Teaching Content $\mathrm{U}_{1}$} & $\begin{array}{l}\text { Imparting rich knowledge, views right, rationality on } \\
\text { handling the emphasis and difficulty } U_{11}\end{array}$ \\
\hline & $\begin{array}{l}\text { Emphasis on basic theory knowledge and skills, with } \\
\text { practice and proper example } U_{12}\end{array}$ \\
\hline & $\begin{array}{l}\text { Explain profound theories in simple language, the } \\
\text { contents of skill, with ease } U_{13}\end{array}$ \\
\hline \multirow{5}{*}{ Teaching Capability $\mathrm{U}_{2}$} & $\begin{array}{l}\text { Subject characteristics and teaching methods for student } \\
\text { characteristics, focusing on student learning guide } U_{21}\end{array}$ \\
\hline & $\begin{array}{l}\text { Accurate and fluent language, articulate speech, concise } \\
\text { expression and compelling lectures } U_{22}\end{array}$ \\
\hline & $\begin{array}{l}\text { Neat writing on the blackboard, (captions) designed } \\
\text { rationalU } U_{23}\end{array}$ \\
\hline & Q \& A, correcting homework seriousness $\mathrm{U}_{24}$ \\
\hline & $\begin{array}{l}\text { Reasonable use of teaching methods, focusing on } \\
\text { inspiring students to active thinking } U_{25}\end{array}$ \\
\hline \multirow{3}{*}{$\begin{array}{l}\text { Imparting knowledge and } \\
\text { educating people } U_{3}\end{array}$} & $\begin{array}{l}\text { The introduction of new scientific and technological } \\
\text { achievements, enhance their self-confidence of national } \\
\text { pride and learning } U_{31}\end{array}$ \\
\hline & $\begin{array}{l}\text { The proper combination of lectures to guide students to } \\
\text { establish a correct outlook on life and values } U_{32}\end{array}$ \\
\hline & $\begin{array}{l}\text { Combination of lectures to introduce the latest knowledge } \\
\text { and academic development } U_{33}\end{array}$ \\
\hline \multirow{3}{*}{ Teaching Effect $\mathrm{U}_{4}$} & $\begin{array}{l}\text { By teaching, improve student interested in the discipline } \\
\mathrm{U}_{41}\end{array}$ \\
\hline & $\begin{array}{l}\text { By teaching, improve students the ability to understand } \\
\text { the problems and solve problems } U_{42}\end{array}$ \\
\hline & $\begin{array}{l}\text { By teaching, inspiring students to achieve the effect of } \\
\text { replication } U_{43}\end{array}$ \\
\hline
\end{tabular}




\section{3. introduction of design ideas of expert system}

Expert system is an important branch of Artificial Intelligence (AI). It is widely applied in medical diagnosis, image processing, petrochemical, geological exploration, financial decision-making, real-time monitoring, molecular genetic engineering, teaching, military and other fields. Expert System is a computer program system with problems solving ability like expert in the relevant areas. With the expert's experiences and expertise in the field, it can simulate the expert's thought process and decision-making capacity to solve the difficult problems only solved by the experts [3]. The general structure is shown in Fig.

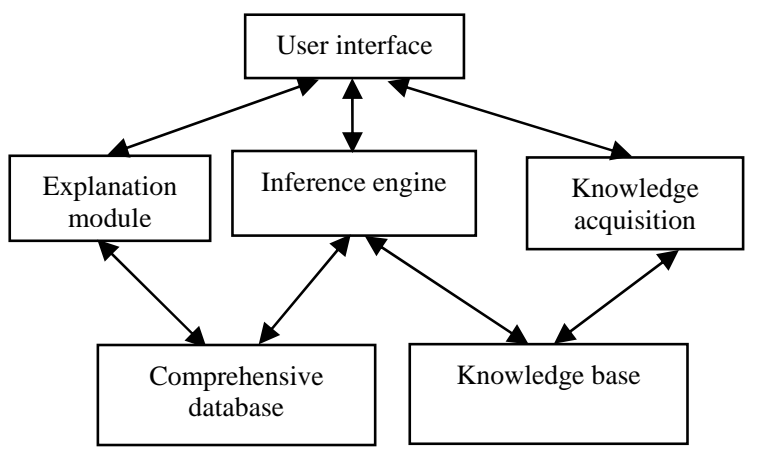

Figure 1. Expert system structure

\section{A. Construction of Knowledge Base}

Knowledge base of basic situation includes the semester plan, schedule cases, basic information of students and teachers, knowledge of basic information and so on.

Knowledge Base of evaluation rules includes the evaluation index system knowledge, type knowledge, specific targets knowledge and optional knowledge. Specific targets knowledge is shown in Table 1.

\section{B. Dealing with uncertainty}

Supervisory experts, faculty leadership and students often use the vague comments like "very good", "good", "fair", and "poor" to evaluate teaching quality. Considering the actual process of teaching evaluation, the poor availability of the existing system is due to the uncertainty of teaching evaluation and tightness between the evaluation of results with data and analysis software. To this end, the separation of inference engine and knowledge base is introduced into teaching quality evaluation system; expert system with fuzzy objective things in the solution evaluation model is constructed. Uncertainty as the degree of membership or the possibility of a fuzzy operator is defined to reflect the variety of uncertainty propagation. It uses fuzzy algorithms of fuzzy mathematics for evaluation of non-linear integrated to quantify the domain, to get the comparable results of quantitative evaluation.

The uncertainty model based on fuzzy logic and possibility theory is a kind of promising models in the expert system to deal with the uncertainty problems, the teaching quality evaluation itself is a typical uncertainty problem. This paper uses fuzzy model to construct the system. 


\section{4. construction of fuzzy evaluation model}

\section{A. Teaching evaluation Index set $U$}

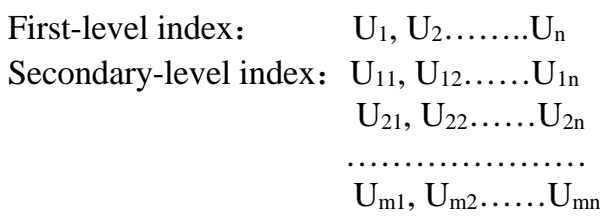

Teaching is a complex intellectual activity. It involves not only knowledge of the course taught, but also Education, Psychology, Linguistics, etc. Therefore, to evaluate teaching quality, many factors should be considered. First-level indexes include the teaching content, teaching ability, imparting knowledge and educating people; secondary-level indexes include imparting rich knowledge, views right, rationality on handling the emphasis and difficulty, which are shown in Table 1.

\section{B. Grades of reviews set $V$}

Grades of reviews are the direct description of evaluation results. The purpose of evaluation is to give comprehensive reviews from the start of the evaluation factors, considering the circumstances of each teacher. Evaluation results can be divided into five grades, that is,

$\mathrm{V} \quad$ outstanding, very good, good, fair, poor

As the evaluation focused on the level of value is vague, that is, its value changes in a certain range, not easy to calculate. So in practice, a specific numerical value used to represent. Here we can set 95, 85,75,60,50.

\section{Establishment of weights set}

Considering the evaluation factors, the importance of each factor is different. Continuous feedback and revision are made through the exchanges of experts and inspectors, and the basic principles of AHP are used to determine the weight of each factor [4]. Here the weights show a certain degree of influence on the final result. For example, in the teaching ability aspect, experts think the factors that affect the quality of teaching is mainly teaching methods, followed by the training analysis, inspired by induction, attractive, and other factors.

Set the weight set of the first-level index is $W=\left\{W_{1}, W_{2}, W_{3}, W_{4}\right\}$, the weight set of the secondary-level index is $\mathrm{W}_{\mathrm{i}}=\left\{\mathrm{W}_{\mathrm{i} 1}, \mathrm{~W}_{\mathrm{i} 2}, \ldots \ldots . ., \mathrm{W}_{\mathrm{im}}\right\}, \mathrm{i}=1,2,3,4 \mathrm{~m}=3,5$. Make an example of calculating the weight of the firstlevel index, the algorithm is as follows:

- $\quad$ Determine the first-level index set $U=\left\{U_{1}, U_{2}, U_{3}, U_{4}\right\}$; then construct the matrix A, denoted $A=\left(a_{i j}\right)$. $a_{i j}$ represents the relative importance of values from $U_{i}$ to $U_{j}$. The quantitative value of the rules is given by experts. Satisfy $a_{i j}>0$, if $a_{i j}=1 / a_{i j}$, then $a_{i j}=1$.

- Consistency ratio, $\mathrm{CR}=\frac{\mathrm{CI}}{\mathrm{RI}}, \mathrm{CI}=\frac{\lambda_{\max }-\mathrm{n}}{\mathrm{n}-1}$ (CI for the consistency index, $\lambda_{\max }$ can be obtained by the formula $\lambda \mathrm{E}-\mathrm{A} \mid=0$ ), RI for the average random consistency index. $\mathrm{CR}<0.1$, shows that the distribution of the weight is reasonable, or need an expert to adjust. $\lambda$ corresponds to normalized vector obtained $\mathrm{W}$ as a weighting factor. Evaluation factors for the weight of the secondary can take the same approach.

\section{Establishment of the fuzzy relationship matrix $R$}

The fuzzy relationship matrix of evaluation from $\mathrm{U}$ to the reviews rating $\mathrm{V}$ called factor evaluation matrix. 
$R=\left(r_{i j}\right)_{m \times n}\left[\begin{array}{llll}r_{11} & r_{12} & \cdots & r_{1 n} \\ r_{21} & r_{22} & \cdots & r_{2 n} \\ \vdots & \vdots & & \vdots \\ r_{m 1} & r_{m 2} & \cdots & r_{m n}\end{array}\right], r_{i j}=\mu_{R}\left(U_{i}, V_{j}\right),(r \in[0,1])$

is the degree of membership from the ith factor of $U$ to the jth factor of $V$. Each secondary factor $U_{i j}$ can get a $\mathrm{R}_{\mathrm{i}}$, the fuzzy relationship matrix of $\mathrm{U}_{\mathrm{i}}$ on $\mathrm{V}$ domain is

$\mathrm{R}_{\mathrm{i}}=\left(\mathrm{B}_{1}, \mathrm{~B}_{2}, \mathrm{~B}_{3}, \mathrm{~B}_{4}, \mathrm{~B}_{5}\right)^{\mathrm{T}}, \mathrm{B}_{\mathrm{i}}=\mathrm{W}_{\mathrm{ij}} \bullet \mathrm{R}_{\mathrm{ij}}$ is $\mathrm{W}_{\mathrm{ij}}$ and $\mathrm{R}_{\mathrm{ij}}$ for the completion operation of $(\bullet, \oplus)$.The fuzzy transformation vector obtained by a judge. The fuzzy evaluation value of $U_{i}$ is $B=W i \bullet R i=\left(b_{1}, b_{2}, b_{3}, b_{4}\right.$, $\left.\mathrm{b}_{5}\right)$.

\section{E. The results of fuzzy comprehensive evaluation}

After determining the weight set $\mathrm{W}$ and the fuzzy relationship matrix $\mathrm{R}$, repeat the above calculation process, to get the fuzzy comprehensive evaluation result of the teaching quality (U) $B=W \bullet R$. According to the principle of maximum degree of membership, the largest number in the $\left(b_{1}, b_{2}, b_{3}, b_{4}, b_{5}\right)$ corresponding to the grade of reviews is the result of the teacher's evaluation. The specific score can be calculated and the quantitative result can be obtained:

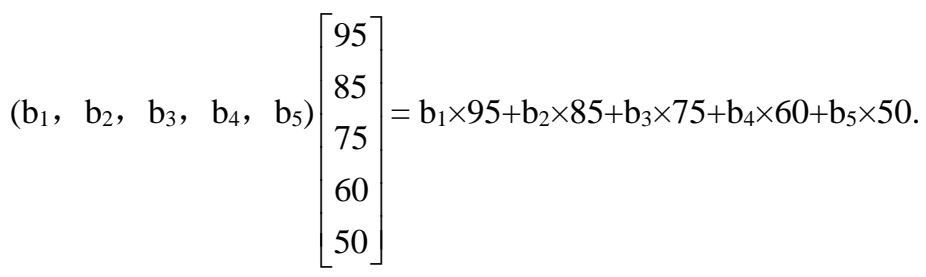

\section{Design of teaching quality evaluation system}

The teaching quality evaluation system is designed to meet the actual demands of my school.

\section{A. Flow analysis of the system}

The administrator prepares the relevant evaluation data and set the course evaluation, evaluators (supervisory experts, faculty leadership, students) login system with their own authority to evaluate and query results. Teachers could scan their own evaluation information. After all the evaluation are finished, the administrator gets into the system, calls the system and summarizes the overall scores of the evaluated object for querying statistics.

Fig. 2 shows the flow chart of teaching quality evaluation system.

\section{B. Implementation of the system}

The Implementation of teaching quality evaluation system depends on the foreground of the computer language and some background systems support. The system has been developed by using the combination of B / S mode and C/ S mode, and SQL Sever2005 as the background database. The evaluation index establishment is shown in Fig. 3. After completing the teaching evaluation, teachers could scan the results and the school administrators could query all the result shown in Fig. 4. By scanning the result, teachers could discover teaching problems, to revise and improve the teaching quality. The whole school could reform teaching positively to promote the teaching quality. 


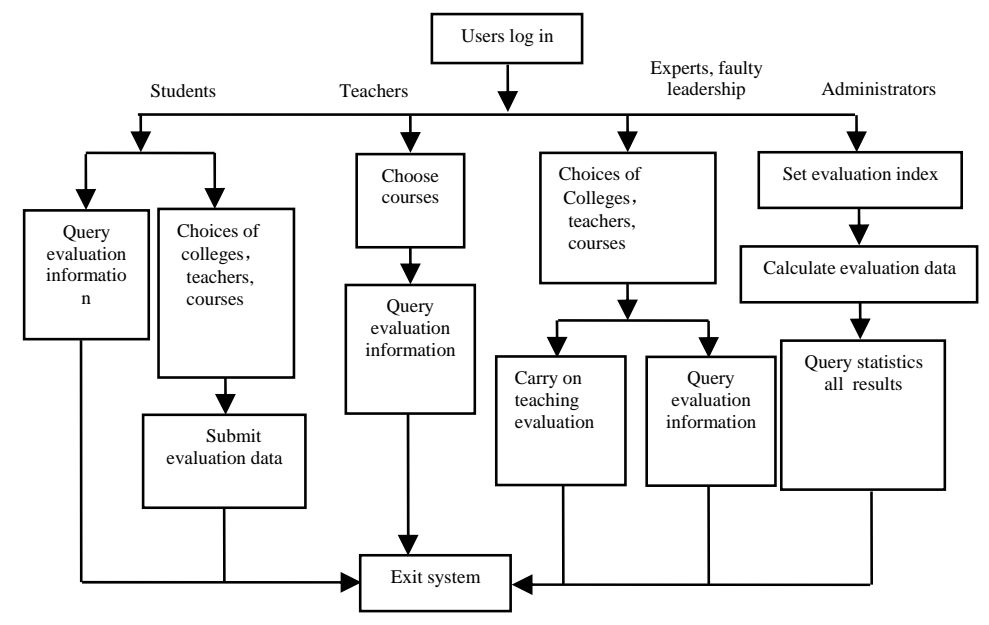

Figure 2. Flow chart of the evaluation system

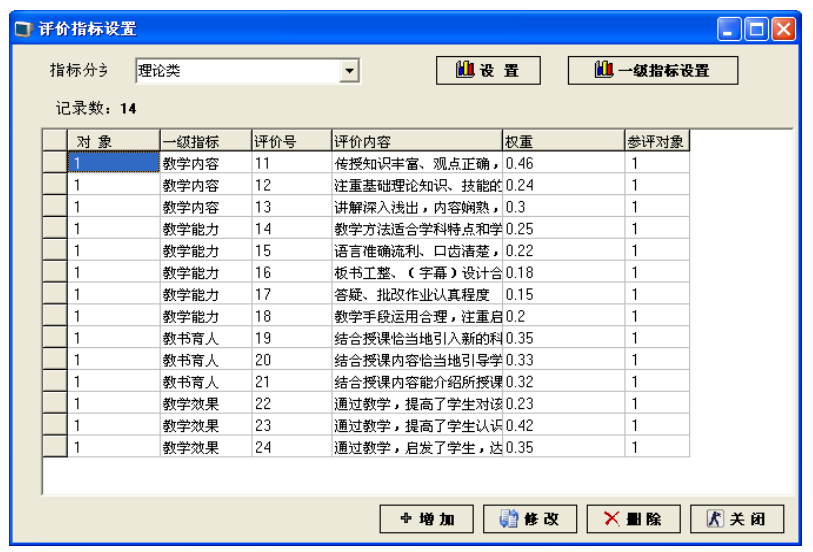

Figure 3. Establishment of the evaluation index

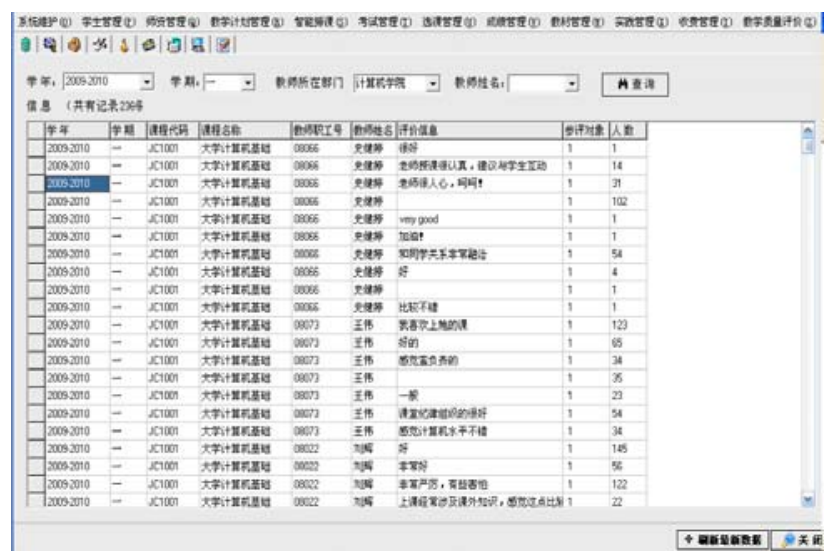

Figure 4. Evaluation opinions chart 


\section{Conclusions}

Teaching quality is the decisive factor in the quality of personnel training [5]. Evaluate the quality is an effective method to test teaching. Teaching quality evaluation is a typical uncertainty problem. Combined with my school's teaching evaluation indexes, this paper proposes the design scheme of teaching evaluation system based on fuzzy model in accordance with experts knowledge and experience. The system has passed the test and achieved the desired results, simple interface, easy to operate. In addition, the system has some deficiencies, to be further improved.

\section{References}

[1] Yi Wu, "Statistical Analysis \& Strategy for Assessment of Undergraduate Programs”, MEI TAN Higher Education,2006, 24 (4) (in chinese)

[2] Hong Song, Xiujie Li, Changchun Wang, “On the Management System of Teaching System” ,Social Sciences Journal of Colleges of Shanxi, 2007, 19 (12) (in chinese)

[3] Michael Negnevitsky,“Artificial Intelligence”, Addison Wesley, 2004

[4] Hui Wang, "Research and Implementation of College Teaching Quality Evaluation System Based on Expert System”[D], Hefei:Hefei University of Technology, 2007 (in chinese)

[5] Lujie Tang, "Design of Higher Education Teaching Quality Evaluation System ”, Journal of Kaili Unversity,2009, 27(3) (in chinese) 